\title{
Optimization of Routine Eye Examination in Asymptomatic Patients in Tertiary Eye Care Center in Western Uttar Pradesh
}

\author{
Antriksha Agarwal ${ }^{1}$, Mahendra Singh², Gaurav Dubey ${ }^{3}$, Jamshed Ali ${ }^{*}$, Riya Saxena ${ }^{1}$, \\ DrAhateshaam Ansari ${ }^{4}$, Ashish Kumar Mishra ${ }^{5}$, Chanchal Verma ${ }^{6}$, Jabed Ali $^{7}$ and Md \\ Masihhuzzaman ${ }^{8}$ \\ ${ }^{1}$ Department of Optometry, Allied Health SciencesInstitute of Management \\ and Technical Studies University (IIMTU), Meerut, U.P. \\ ${ }^{2}$ Department of Optometry and Vision Science, CL Gupta Eye Institute Moradabad U.P. \\ ${ }^{3}$ Department of Optometry, Faculty of Paramedical Sciences, UPUMS, Saifai, Etawah U.P. \\ ${ }^{4}$ Department of Physiotherapy, Allied Health SciencesInstitute of Management \\ and Technical Studies University (IIMTU), Meerut, U.P. \\ ${ }^{5}$ School of pharmaceutical sciences, IIMT, University Meerut,U.P. \\ ${ }^{6}$ Department of BMLT, Allied Health Sciences,Institute of Management and \\ Technical Stud-ies University ( IIMTU), Meerut, U.P. \\ ${ }^{7}$ Consultant Optometrist, Biratnagar, Eye Hospital, Nepal. \\ ${ }^{8}$ Department of Optometry, Amity Medical School, Haryana \\ Corresponding author email: alijamshed429@gmail.com
}

\section{ABSTRACT}

An eye examination is a series of tests performed by an ophthalmologist and optometrist as-sessing vision and ability to focus on objectsand other tests and examinations pertaining to the eyes. It is important to determine the percentage of asymptomatic patients of all age groups.Routine eye examinationsresult in spectacle prescription change, new critical diagno-sis, or new management of existing conditions.This study aimsto identify the visual/eye con-ditions and their functioning in an asymptomatic patient.A prospective study carried out among the enrolled participants. A total of 400 eyes of 200 asymptomatic patient's data were analysed. Out of which 98 (49.0\%) were male, and $102(51.0 \%)$ female. The mean age of the patient was $33.87 \pm 21.09$ years. A comprehensive eye examination used to analyse the visual condition. $40(20 \%)$ patients were aware of systemic disease, and $160(80 \%)$ were unaware. 112 (56\%) patients already having glasses and 88 (44\%) were not, 101 (50.5\%) patients hav-ing a change in their PGP, and 99 (49.5\%) were not having any change.This study concludes that it is important for everyone to have a routine eye examination.

KEY WORDS: ROUTINE EYE EXAMINATION ( REE) AND ASYMPTOMATICPSTIENTS, PREVIOUS GLASS PRRSECRIPTION (PGP), EYE HEALTH.

\section{INTRODUCTION}

An eye examination is a series of tests performed by an ophthalmologist and optometrist to evaluate eyesight and

Biosc Biotech Res Comm P-ISSN: 0974-6455 E-ISSN: 2321-4007

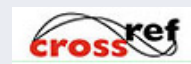

Identifiers and Pagination

Year: 2021 Vol: 14 No (7) Special Issue

Pages: 186-190

This is an open access article under Creative

Commons License Attribn 4.0 Intl (CC-BY).

DOI: http://dx.doi.org/10.21786/bbrc/14.7.44 ability to focus on objects, as well as other eye-related tests and exami-nations. Because many eye illnesses are asymptomatic, health care specialists recommend that all persons receive periodic and thorough eye examinations as part of routine primary care. There is a need to determine the proportion of asymptomatic patients across all age groups. Routine eye exams (REEs) may result in a change in spectacle prescription, a new significant diagnosis. The quality of life of a person is closely related to vision and eye health (Feder et al 2016 and Ali, et al 2021). Furthermore, the economic impact of vision loss is significant.

\section{Article Information}

Received: $10^{\text {th }}$ May 2021

Accepted after revision: $14^{\text {th }}$ July 2021 
Comprehensive eye examinations can help avoid vision loss in such circumstances by screen-ing asymptomatic diseases. According to one study, more than half of asymptomatic people who had a standard eye exam had a change in ocular condition or care, compared to $77 \%$ of symptomatic people who had a routine eye exam (Brown et al., 2001). Children and adolescents should have their visual vision tested if they complain of headaches or focus de-ficiency while performing near vision activities (Chan et al., 2014). Similarly, the evi-dence rationalizes the frequency of eye examinations for individuals at high risk of acquiring ocular disorders, such as those with diabetes (Fraser et al., 2001). In contrast, the ideal REE frequency in asymptomatic patients is unknown. Because visual outcomes and associated ex-penses vary with age, recommendations should be age-specific (Hussain et al., 2020, Jin et al 2012 and Kristinsson et al., 1997).

Many disorders treated if they diagnosed at an advanced stage. Comprehensive routine eye examinations (REE) play a preventive role in vision loss by screening for asymptomatic eye illness. Routine eye examinations are thus essential for both symptomatic and asymptomatic people. Asymptomatic eye disease affects between 14 and 26 percent of persons, and accord-ing to Quigley, it affects less than half of those with glaucoma (KAHN, et al 1977 and Klaver et al 1998). Therefore,our study aims to examine if routine eye exams in asymp-tomatic patients result in a change in spectacle prescription or the development of a new di-agnostic criterion.

\section{METHODOLOGY}

This prospective study conducted at CL Gupta Eye Institute of Moradabad District, U.P, In-dia, from July 2017- Feb 2018. The institutional ethical committee approved the studyfrom theDepartment of Optometry and Vision Science.The data were collected daily from the patient's assessment sheet and history, maintained by the medical record department(MRD), for patients who visited the tertiary eye hospital for a routine eye examination and were assessed by the qualified ophthalmologist Optometrist. The visually asymptomatic REEofpatients of all age groups with no eye-related symptoms, e.g., headaches, diplopia, blurred vision, flashes and floaters, or with anyrefractive error(RE), was included in the stud. Those who initially presented for an REE but reported symptoms when specifically questioned excluded from the study.A total of 400 eyes of 200 asymptomatic patientsobtained.A spectacle prescription change was significant if in at least one eye, the Sph, Cyl or any reading addition power changed by $\pm 0.5 \mathrm{D}$ from the initial phase to the existing spectacleprescription.

Statistical Analysis: The collected data from the questionnaire and comprehensive eye examination and demo-graphic data was transcribed to Microsoft Excel for further analysis. The Statistical Package for Social Sciences (SPSS) Version 16 was used; The data collected from the clinical test were analysed using Microsoft Excel (2017) and SPSS software (version 17.0 for Windows, SPSS Inc., Chicago, IL, USA).

\section{RESULTS AND DISCUSSION}

The 400 eyes of 200 patients were analysed.The demographic variables include medical rec-ord number (MR.NO), Age, Gender, any Systemic history, using glasses or not, duration and last Previous glass prescription (PGP), duration and power, new spectacle prescription, change in glasses, Diagnosis, and Management. (Table-1) The mean age of the patient was $33.87 \pm 21.09$ years. 98(49.0\%) of them were male, and $102(51.0 \%)$ were female.(Graph-1)40(20\%) patients were aware of systemic disease, and $160(80 \%)$ were unaware. $112(56 \%)$ patients already having glasses and 88 (44\%) were not; out of 112 patients, $50(44.6 \%)$ were having a change in their PGP and 47 (41.9\%) were not re-quire any treatment and 15 (13.3\%) were having some other pathologies.(Graph-2) Out of 88 patients, 48 (54\%) were prescribed glasses, 32 $(36 \%)$ were not require any treat-ment and $8(9 \%)$ were having some other pathologies.101 (50.5\%) patients having a change in their PGP, and $99(49.5 \%)$ were not having any change. (Table-2) (Table-3).

Out of 200 asymptomatic patients documented, 44\% Table 1. Demographic characteristics of studied population

\begin{tabular}{|l|c|c|c|c|c|}
\hline Variables & Total & Min & Max & Mean & $\begin{array}{c}\text { Std. } \\
\text { Deviation }\end{array}$ \\
\hline Age & 200 & 3 & 86 & 33.86 & \pm 21.1 \\
\hline Using Glasses & 200 & 0 & 440 & 52.86 & \pm 125.7 \\
\hline Last PGP(months) & 200 & 0 & 240 & 18.11 & \pm 35.06 \\
\hline
\end{tabular}

Graph 1: Gender Distribution

\section{Responses}

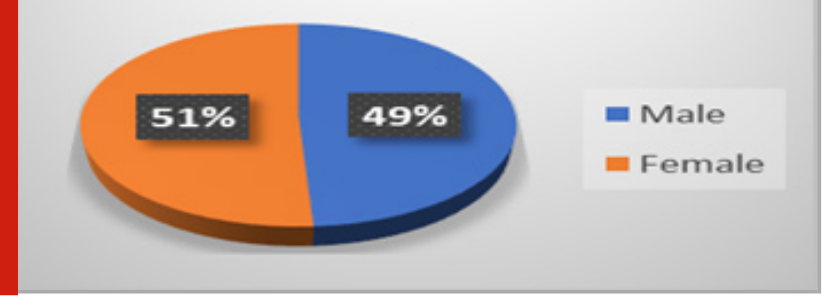

were not using glasses. (58\%) of asymptomatic patients presented for an REE and had a change in ocular statuscomparedwith (77\%) of symptomatic REE patients. In symptomless patients,age is a strong predictor of having a significant difference. This was true regardless of the assessment interval and corresponds well withknown age-related ocular changes such as presbyopia and increasingpreva-lence of eye disease. It also makes sense that the odds of having a significant change also in-creased when the assessment intervalincreased. 
Table 2. Estimation of various variables among the studied population

\begin{tabular}{|c|c|c|c|c|c|c|c|c|c|}
\hline GENDER & & \multicolumn{8}{|c|}{ AGE GROUP } \\
\hline Male & Female & $0-5$ & $6-10$ & $11-18$ & $19-30$ & $31-50$ & \multicolumn{3}{|l|}{$>50$} \\
\hline $102(51 \%)$ & $98(49 \%)$ & $11(5.5 \%)$ & $24(12 \%)$ & $27(13.5 \%)$ & $37(18.5 \%)$ & $45(22.5 \%)$ & \multicolumn{3}{|l|}{$56(28 \%)$} \\
\hline \multicolumn{2}{|c|}{$\begin{array}{l}\text { CHANGE N } \\
\text { PRESCRIPTION } \\
(\mathrm{N}=\mathbf{2 0 0})\end{array}$} & \multicolumn{8}{|c|}{$\begin{array}{l}\text { PREVIOUS GLASS PRESCRIPTION } \\
(\mathrm{N}=\mathbf{2 0 0})\end{array}$} \\
\hline \multirow[t]{2}{*}{$\mathrm{Y}$} & \multirow[t]{2}{*}{$\mathbf{N}$} & \multicolumn{2}{|l|}{ GLASSES } & \multicolumn{2}{|c|}{$\begin{array}{lll}\text { NO } & \text { TREATMENT } \\
\text { CSG } & & \text { OR }\end{array}$} & \multicolumn{4}{|c|}{ OTHER PATHOLOGY } \\
\hline & & $\mathrm{Y}$ & $\mathrm{N}$ & $\mathrm{Y}$ & $\mathbf{N}$ & $\mathrm{Y}$ & \multicolumn{3}{|l|}{$\mathrm{N}$} \\
\hline $101(50.5 \%)$ & $99(49.5 \%)$ & $50(44.6 \%)$ & $48(54 \%)$ & $47(41.9 \%)$ & $32(36 \%)$ & $15(13.3 \%)$ & \multicolumn{2}{|c|}{$8(9 \%)$} & \\
\hline \multicolumn{10}{|c|}{ SYSTEMIC DISEASES $(\mathrm{n}=\mathbf{2 0 0})$} \\
\hline HTN & \begin{tabular}{|l|} 
Cholesterol \\
\end{tabular} & $\mathrm{DM}$ & \begin{tabular}{|l|} 
DM, \\
Asthma, \\
CAD
\end{tabular} & HTN, DM & DM, CAD & HTN,CAD,DM & Thyroid & Not aware of & \\
\hline $15(7.5 \%)$ & $1(0.5 \%)$ & $9(4.5 \%)$ & $1(0.5 \%)$ & $11(5.5 \%)$ & $1(0.5)$ & $1(0.5 \%)$ & $1(0.5 \%)$ & $160(80 \%)$ & \\
\hline \multicolumn{10}{|c|}{ FUNDUS EXAMINATION $(n=400)$} \\
\hline $\begin{array}{l}\text { Retina On, No } \\
\text { Treatable Lesion }\end{array}$ & \begin{tabular}{|l|} 
Small \\
Hyperemic Disc
\end{tabular} & $\begin{array}{l}\text { Micro } \\
\text { Aneurysms }\end{array}$ & \begin{tabular}{|l|} 
Myopic \\
Tessellated \\
Fundus
\end{tabular} & \begin{tabular}{l|l} 
d & Retina \\
On, Total \\
Near \\
Cupping
\end{tabular} & \begin{tabular}{|l|}
$0.7: 1$ \\
Inferior \\
Rim \\
Thinning \\
\end{tabular} & 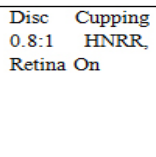 & $\begin{array}{l}\text { Disc } \\
\text { Cupping } \\
0.9: 1 \\
\text { HNRR, } \\
\text { Retina } \\
\text { On }\end{array}$ & $\begin{array}{l}\text { Lattice } \\
\text { Degeneration, } \\
\text { inferiorly }\end{array}$ & $\begin{array}{l}\text { Choroidal } \\
\text { Colobomalnfero- } \\
\text { Nasally with } \\
\text { Hazy View }\end{array}$ \\
\hline $376(94 \%)$ & $3(0.75 \%)$ & $2(0.5 \%)$ & $2(0.5 \%)$ & $2(0.5 \%)$ & $2(0.5 \%)$ & $1(0.25)$ & $1(0.25)$ & $1(0.25)$ & $1(0.25)$ \\
\hline
\end{tabular}

\section{FUNDUS EXAMINATION ( $\mathrm{n}=400)$}

\begin{tabular}{|l|l|l|l|l|l|l|l||}
\hline Microaneurysms, & Microaneurysms, & CRA & No View, & Retina & Retina & CRA Patches & Tessellated Myopic Fundus, \\
NVE & NVE, DME & $\begin{array}{l}\text { Patches } \\
\text { Inferiorly }\end{array}$ & Differ & $\begin{array}{l}\text { On, } \\
\text { Macular } \\
\text { Scar, With } \\
\text { Hazy } \\
\text { View }\end{array}$ & $\begin{array}{l}\text { Near the } \\
\text { Macula Area }\end{array}$ & \\
\hline $1(0.25)$ & $1(0.25)$ & $1(0.25)$ & $1(0.25)$ & $1(0.25)$ & $1(0.25)$ & $1(0.25)$ & $1(0.25)$ \\
\hline
\end{tabular}

Where $Y$ Indicates $=$ Yes; N Indicate=No; HTN= Hypertension; DM= Diabetics Mellitus; $\mathrm{CAD}=$ Coronary Artery Disease; HNRR= Healthy Neuro Retinal Rim;NVE=Neovasculartzation Elsewhere ; DME=Diabetic Macular Edema ;CRA = Central Retinal Artery

Graph 2: Estimation of previous prescribe glasses among asymptomatic patients.

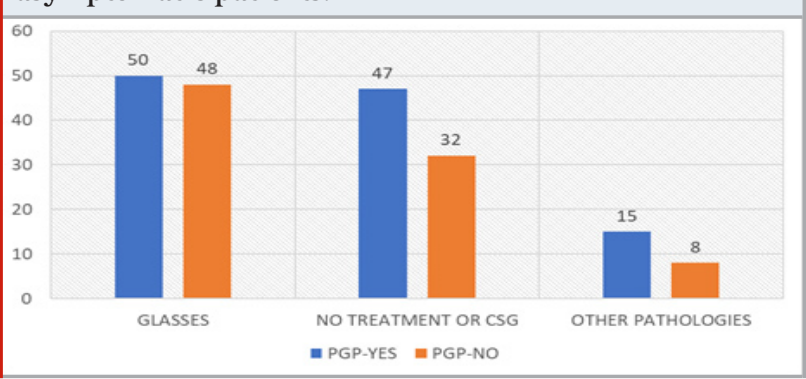

It observed thatthe longer a patient waits for their following assessment, themore chances of increasing their risk of age-relatedconditions. However, we also found an association between assessmentinterval and detection of a signif-icant change when controllingfor age. Although the association between age and assessment intervaldoes play a role, it is not the sole explanation. More significant assessmentintervals would allow more time for a disease or condition to develop, irrespective of age.Many factors influence the assessment interval for patients, including patient age, cost of the examination, insurance coverage, recommendations given by practitioners or professionalbodies, andpatients' perceived risk of visual impairment and their understandingof the consequences of not seeking eye care.

The observedmedian assessment interval for the various asymptomatic REE agegroups matches the recommended optometric guidelines more closelyto the age-relatedcause in the currentstudy. Apparently, this can be due to the approach of how practitioners instruct them. REEs for patients aged 20 to 64 yearswere not publicly funded except for 8 defined medical conditions.Annual REEs for patients G20 and 964 years were publiclyfunded (Michaud 
and Forcier 2014). It showed that de-insurance of eye examinationsreduced the uptake of eye examinations for people in lower-income levels. Funded age groups had smaller time in-tervals betweenassessments than non- funded age groups, suggesting thatthose with aboveaverage socioeconomic statusmay also be affectedby a lack of insurance or public funding.

Table 3. Documented diagnosis and Interventions among asymptomatic patients.

\begin{tabular}{|c|c|c|c|}
\hline DIAGNOSIS $(\mathrm{n}=400)$ & Frequency & INTERVENTION(n=400) & Frequency \\
\hline Myopia & $136(34 \%)$ & New glasses & $196(49 \%)$ \\
\hline Emmetropia & $67(16.75 \%)$ & Continue same glasses & $96(24 \%)$ \\
\hline Hypermetropia with presbyo-pia & $53(13.25 \%)$ & No treatment required & $70(17.5 \%)$ \\
\hline Presbyopia & $36(9 \%)$ & Cataract surgery & $18(4.5 \%)$ \\
\hline Hypermetropia & $24(6 \%)$ & Eye drop & $9(0.2 \%)$ \\
\hline Cataract & $22(5.5 \%)$ & YAG PI & $2(0.5 \%)$ \\
\hline Myopia with presbyopia & $15(3.75 \%)$ & $\begin{array}{l}\text { Continue same glasses } \\
\text { and alternate patching }\end{array}$ & $2(0.5 \%)$ \\
\hline Early Cataract & $10(2.5 \%)$ & Need P.R.P & $2(0.5 \%)$ \\
\hline Pseudophakia & $8(2 \%)$ & Eviscerations & $1(0.3 \%)$ \\
\hline Disc Suspect & $3(0.75 \%)$ & LVA -Magnifier +5 & $1(0.3 \%)$ \\
\hline NPDR & $2(0.5 \%)$ & Alternative Patching (OU) & $1(0.3 \%)$ \\
\hline Myopia with intermittent exotropia & $2(0.5 \%)$ & OCT & $1(0.3 \%)$ \\
\hline Myopia with exotropia & $2(0.5 \%)$ & SIP Trab- & $1(0.3 \%)$ \\
\hline Hypermetropia with ametrop-ic amblyopia & $2(0.5 \%)$ & & \\
\hline Emmetropia with meibomitis & $2(0.5 \%)$ & & \\
\hline Myopia and dry eye & $2(0.5 \%)$ & & \\
\hline C.M.E -P.D.R & $1(0.25 \%)$ & & \\
\hline Closure angle glaucoma & $2(0.5 \%)$ & & \\
\hline Hypermetropia with presbyo-pia and P.O.A.G & $1(0.25 \%)$ & & \\
\hline Macular Scar & $1(0.25 \%)$ & & \\
\hline Total Glaucomatous Atrophy & $1(0.25 \%)$ & & \\
\hline Cataract and iris coloboma & $1(0.25 \%)$ & & \\
\hline Anisometropic Amblyopia with presbyopia & $1(0.25 \%)$ & & \\
\hline Absolute Glaucoma & $1(0.25 \%)$ & & \\
\hline P.D.R & $1(0.25 \%)$ & & \\
\hline Phthisical eye & $1(0.25 \%)$ & & \\
\hline
\end{tabular}

Furthermore, based on the Canadian Longitudinal National Population Health Survey data, regions where REEs were not funded had reduced patient awareness about glaucoma, cata-racts, and vision loss for patients aged above 65 years (Robinson et al., 2012). It is diff1cult to compare our data with the existing literature because the age groups, study popula-tions, diagnosis, exclusion criteriaand time of studies mayreflect the scope of practice and may increase 1.25 times per year since the last visit to a hospital in studiedpatients with newly diagnosed glaucoma and adjustedodds ratios (Hussain et al., 2020).

The WatES clinic population does compare favourably in terms of patient age and sex distri-bution to a nationwide survey of Canadian optometric practicesfoundthat $32.6 \%$ of patients that presented to optometric practices camefor an REE and expressed no concerns compared with $41 \%$ of theWatES clinic patient population classified as asymptomatic REEpatients. Both of these values contradictthe claim that asymptomatic patients are rarely seen in an op-tometryclinic. It is possible that many patient symptoms and/or findingsnot recorded despite routine questioning.Missed examination findings would result in conservative esti-mates, whereas missed signs would overestimate significant changes ifasymptomatic person-sare not accidentally included.In general, the assessment intervals of the various asymptomaticREE patient age groups matches the Canadian OptometricGuidelines. 


\section{CONCLUSION}

According to the findings of this study, everyone needs to get a regular eye examination at least once every six months. Patient communication conducted through awareness sessions and instructional materials distributed to patients and practitioners. Routine eye examina-tionsplay an essential role in avoiding vision loss by screening for asymptomatic eye diseases. However, the appropriate frequency of tests for patients who do not have any vision im-pairments or eye-related symptoms is undetermined. Current recommendations differ and are based on expert opinion rather than factual information.

\section{ACKNOWLEDGEMENTS}

The authors thank C L Gupta Eye Institute Moradabad Uttar Pradesh for providing the facili-ties used to carry out this study. We would like to thank all the parents who participated in the study and spared their time to fill the questionnaire.

\section{Conflect of Instrest- None}

\section{REFERENCES}

Ali, J., Sarkar, S., Bakhshi, D. and Hassan, Z (2021). Screening of Convergence Disorders and Accommodation Disorders among School Children in Gorakhpur. European Journal of Molecular \&t Clinical Medicine, 7(10), pp.2706-2723.

Brown, M.M., Brown, G.C., Sharma, S., Kistler, J. and Brown, H., (2001). Utility values associated with blindness in an adult population. British Journal of Ophthalmology, 85(3), pp.327-331.

Chan, C.H., Trope, G.E., Badley, E.M., Buys, Y.M. and Jin, Y.P., (2014). The impact of lack of governmentinsured routine eye examinations on the incidence of self-reported glaucoma, cataracts, and vision loss. Investigative ophthalmology \&t visual science, 55(12), pp.8544-8549.

Feder, R.S., Olsen, T.W., Prum, B.E., Summers, C.G., Olson, R.J., Williams, R.D. and Musch, D.C., 2016.
Comprehensive adult medical eye evaluation Preferred Practice Pat-tern ${ }^{\circledR}$ guidelines. Ophthalmology, 123(1), pp.P209-P236.

Fraser, S., Bunce, C., Wormald, R. and Brunner, E., (2001). Deprivation and late presenta-tion of glaucoma: case-control study. Bmj, 322(7287), pp.639-643.

Hussain, A., Ahmad, S., Sahay, A., Bakhshi, Z.H. and Fatima, N., (2020). Mapping of Au-tism Spectrum Disorders Research: A Bibliometric Analysis of Highly Cited Research Output. International Journal Of Economics, Business And Human Behaviour, 1(3), Pp.71-83..

Jin, Y.P., Buys, Y.M., Hatch, W. And Trope, G.E., (2012). De-Insurance In Ontario Has Reduced Use Of Eye Care Services By The Socially Disadvantaged. Canadian Journal Of Ophthalmology, 47(3), Pp.203-210.

Kahn, H.A., Leibowitz, H.M., Ganley, J.P., Kini, M.M., Colton, T., Nickerson, R.S. And Dawber, T.R., (1977). The Framingham Eye Study: I. Outline And Major Prevalence Find-ings. American Journal Of Epidemiology, 106(1), Pp.17-32.

Klaver, C.C., Wolfs, R.C., Vingerling, J.R., Hofman, A. and de Jong, P.T., (1998). Age-specific prevalence and causes of blindness and visual impairment in an older population: the Rotterdam Study. Archives of ophthalmology, 116(5), pp.653-658.

Kristinsson, J.K., Hauksdottir, H., Stefansson, E., Jonasson, F. and Gíslason, I., (1997). Ac-tive prevention in diabetic eye disease: a 4-year follow-up. Acta Ophthalmologica Scandinavica, 75(3), pp.249-254.

Michaud, L. and Forcier, P., (2014). Prevalence of asymptomatic ocular conditions in sub-jects with refractive-based symptoms. Journal of optometry, 7(3), pp.153-160.

Robinson, B.E., Mairs, K., Glenny, C. and Stolee, P., (2012). An evidence-based guideline for the frequency of optometric eye examinations. Primary Health Care, 121, pp.2167-1079.

Wang, F., Ford, D., Tielsch, J.M., Quigley, H.A. and Whelton, P.K., (1994). Undetected eye disease in a primary care clinic population. Archives of internal medicine, 154(16), pp.1821-1828. 